\title{
Entrevista*
}

\section{Terry Cook}

Desde 1998, Terry Cook é professor visitante do programa de pós-graduação em Estudos de Arquivologia do Departamento de História da Universidade de Manitoba, Winnipeg, Canadá, como também é consultor em arquivologia, editor freelance e escritor. Ele também administrou cursos em ciência arquivística na Universidade de Michigan (Estados Unidos) e na Universidade Monash (Austrália). De 1975 a 1998, ele foi arquivista, gerente e executivo sênior do Arquivo Nacional do Canadá, agora Biblioteca e Arquivos do Canadá, onde foi o diretor responsável pela avaliação e eliminação de documentos em todo o tipo de mídia para o governo do Canadá. Ele também desenvolveu várias e influentes políticas e estratégias de implementação de Arquivos Nacionais nas áreas de macro-avaliação, amostragem, documentos regionais e documentos eletrônicos. Ele adotou tanto a teoria como a prática em sua vida profissional, ou seja, tanto os conceitos sobre fundos de arquivo como as estratégias usadas para colocar estes conceitos na prática do mundo real de documentos e administração pública.

Ele atuou 18 anos, no total, como Editor Geral na Archivaria, a revista acadêmica nacional da Associação Canadense de Arquivistas; como Editor da Associação Histórica Canadense de Documentos Históricos - agora o periódico da Associação; e também foi Editor da série Historical Booklets. Ele também é membro do conselho editorial de periódicos acadêmicos em arquivologia no Canadá, Estados Unidos e Europa.

Além de ter publicado cerca de 80 ensaios, agora em seis continentes, ele escreveu ou editou cinco livros, e está atualmente trabalhando no seu sexto livro, para editoras da França, Holanda, Estados Unidos, Espanha e Canadá, além da autoria de inúmeros guias e inventários publicados para o Arquivo Nacional do Canadá. Foi responsável por institutos de avaliação, documentos digitais, arquivologia pós-moderna e ética arquivística, em todo o Canadá e internacionalmente, especialmente, em várias oportunidades, na Austrália, Irlanda, Espanha e África do Sul; palestrando em várias conferências em todos os continentes, e discursando em plenário para o encontro quadrienal do Congresso Internacional de Arquivos em Pequim, em

\footnotetext{
* Colaboraram nesta entrevista: Profa. Dra. Solange Puntel Mostafa e Prof. Dr. Eduardo Ismael Murguia
}

InCID: R. Ci. Inf. e Doc., Ribeirão Preto, v. 3, n. 2, p. 142-156, jul./dez. 2012. 
1996, e para Mesa Redonda da ACI em Quebec em 2007 e, em Oslo, em 2010. Ele visitou o Brasil em 1997 e proferiu palestras no Rio de Janeiro e em São Paulo.

De 1998 a 2006, ele foi o principal lobista da Associação de Arquivistas Canadenses a preparar apresentações escritas e testemunhar perante o Parlamento canadense sobre questões de políticas de informação federal, tais como privacidade, dados do censo, mídia digital, e a criação da Biblioteca e Arquivos do Canadá. Atualmente, seus principais interesses de pesquisa incluem avaliação arquivística, arquivologia pós-moderna, teoria arquivística, e a história arquivística e ideias arquivísticas. Atualmente está escrevendo um livro sobre a história do Arquivo Público Nacional do Canadá.

Obteve seu doutorado em História na Universidade de Queen em Kingston, Ontário, em 1977. Em sua trajetória de historiador à arquivista, de arquivística tradicional à arquivística pósmoderna, desafiando muitas das premissas básicas de sua profissão, o seu trabalho tem sido reconhecido por diversos prêmios e honrarias, incluindo sua eleição como Membro da Sociedade Americana de Arquivistas, Membro da Society of Canadian Office Automation Professionals, e Membro da Associação Canadense de Arquivistas. Em 2010, ele foi eleito Membro da Sociedade Real do Canadá (o maior reconhecimento para os estudiosos e cientistas em todas as áreas acadêmicas no Canadá), tendo sido o primeiro estudioso da ciência arquivística, como uma disciplina separada, a receber tal honra.

InCID: O senhor estudou história em seu doutorado e editou revistas científicas na área de história e também escreveu ensaios na área. No entanto, tornou-se um arquivista, um arquivista especialmente conhecido por repensar de forma radical a nossa profissão. Qual foi o momento decisivo de virada na sua trajetória? E como a história afetou a sua visão sobre fundos de arquivo?

Terry Cook: Meu campo especial da história era a história intelectual, às vezes chamada de história das ideias. Em história geral, e especialmente na história intelectual, o historiador está sempre tentando responder à pergunta "Por quê?" Por que determinada coisa aconteceu? Por que uma pessoa ou grupo pensou ou agiu de uma determinada maneira? Por que algumas ideias têm influência e outras desvanecem? Por que as pessoas, em algum momento no passado, percebem 
as condições econômicas ou sociais como sendo melhor (ou pior) do que realmente eram, e, portanto, agiram de acordo com suas percepções, suas crenças, suas suposições, ao invés de responder à realidade de fato? É claro que o historiador deve saber o que aconteceu, onde, quando, com quem e como. Mas, para mim, as respostas a estas perguntas fornecem a estrutura, o contexto, que levam à sondagem de respostas para questões mais interessantes sobre os "por quês".

Então, meu momento decisivo foi quando comecei a perguntar "por quê?" logo no início da minha carreira de arquivista, em relação às ideias e processos arquivísticos, ao invés de perguntar sobre tópicos de pesquisa histórica. Por exemplo, por que o princípio da proveniência é tão venerado na nossa profissão, fornecendo um contexto para os documentos, ligando-os à sua instituição de origem, quando claramente havia, para registros governamentais complexos, várias instituições de origens, não apenas uma? Por que a avaliação arquivística foi baseada na tentativa de espelhar tendências de pesquisa na história acadêmica, quando membros de várias outras profissões também usam arquivos, e cada vez mais, para não falar de pessoas que não fazem parte de profissões acadêmicas formais: romancistas, artistas, chefs, dramaturgos, ambientalistas? Por que a profissão arquivística, até cerca de 20 anos atrás, geralmente insistia que o arquivista fosse um guardião, neutro e objetivo, quando a avaliação arquivística, era obviamente, para citar um exemplo, tanto ativa como subjetiva? Por que insistimos em ser percebidos como guardiões de documentos antigos, quando estávamos na verdade a moldar o arquivo. Ao invés de manter arquivos, nós fazemos arquivos. E esse foi o principal momento de virada para mim: nós, como uma profissão, somos tão obcecados em cuidar do produto (o documento, o mapa, a fotografia) que negligenciamos o processo (a função de registrar ou administrar ou a atividade por trás da confecção de mapas, fotografias, ou correspondência), incluindo o processo de arquivar o arquivo. Por que temos os documentos que temos em fundos de arquivos? Por que os descrevemos da forma como fazemos? Por que adotamos uma mitologia profissional de guarda passiva ao invés de mediação ativa com o passado? Por quê?, Por quê?, Por quê? Para encontrar as respostas, eu fui estudar a história da arquivologia para questionar a teoria arquivística através de uma lente pós-moderna. 


\section{InCID: O senhor diz que o princípio fundamental da nossa profissão, o princípio de} proveniência, não merece a atenção que tem recebido tão amplamente. Poderia falar mais sobre isso?

Terry Cook: A intenção do princípio de proveniência era manter os documentos dentro de seu contexto, de modo que seu valor como prova/evidência, fosse mantido. Eu sou um grande defensor da preservação de documentos num contexto rico, sejam estes documentos antigos ou novos registros digitais. O problema é que os pioneiros da arquivologia definiram 'contexto' de forma muito limitada, relacionado à instituição de origem, em uma estrutura burocrática. Eu estou mais interessado no que se passa dentro desta instituição. São as funções, programas e atividades que ocorrem dentro da instituição que geram registros, não a instituição em si. Além disso, a relação próxima de um-para-um que se assume entre função e estrutura na teoria clássica da arquivística, simplesmente não é mais verdadeira nas organizações modernas. As atividades do processo de trabalho e as funções (que estão mais num nível macro) que as produzem, agora existem em muitas instituições, espalhadas pelo espaço geográfico e ao longo do tempo, já não refletindo uma organização mono-hierárquica. $\mathrm{O}$ computador e as revoluções em telecomunicação aceleraram radicalmente esta descentralização e difusão, a tal ponto que as funções operacionais agora atravessam todos as formas de linhas estruturais e organizacionais.

Décadas atrás, Peter Scott e Chris Hurley da Austrália, lamentaram de forma mais proeminente, embora muitos outros internacionalmente acabaram se uniram a eles de forma crescente, 0 fracasso arquivístico em forçar os muitos processos ou funções e atividades múltiplas para a criação de séries e agrupamentos de arquivos em uma única estrutura administrativa para descrever arquivos, e chamando esta proveniência e os documentos resultantes, de fundos de arquivo. Mesmo na época de Jenkinson, o sistema de registro oficial centralizado do próprio governo britânico não chegou a operar na forma clássica assumida pelos primeiros teóricos arquivísticos. Este sistema foi impedido na época, como estudos recentes mostram, por convenções informais, práticas localizadas, expectativas sociais e normas culturais: estes formam o verdadeiro contexto dos arquivos. Estas são as muitas variáveis que os próprios arquivistas devem pesquisar a fim de entender o contexto real e mais profundo, e portanto, serem capazes de executar todas as funções arquivísticas embasados num entendimento muito melhor de contexto e, portanto, de significado de documentos. O conhecimento da pesquisa que os arquivistas 
adquirem sobre o contexto, será então transmitido para os pesquisadores, de modo que os documentos arquivísticos possam ser usados com mais sutileza e nuances.

Em suma, nós arquivistas precisamos nos perguntar: o que acontece à proveniência quando as culturas organizacionais e os discursos do local de trabalho são então transformados de vertical para horizontal, de controlador para colaborador, de foco limitado e sem contexto para o contexto de redes, de decreto executivo para consenso interno, de foco no processo dialógico enriquecido, com documentos criados nestas realidades sociais e culturas organizacionais usando esses novos protocolos, tendo em vista contextos radicalmente diferentes, isto é, um tipo de proveniência radicalmente diferente, enquanto nós ainda assim pensamos hierarquicamente e organizamos nossos arquivos e nossas ferramentas descritivas de acordo com o pensamento estruturalista hierárquico? Ao fazer isso, os arquivos perdem cada vez mais o contato com a realidade do contexto dos documentos na administração moderna, quando ligamos a proveniência de documentos à uma única entidade estruturalista. Falando francamente, essa abordagem, na minha opinião, faz com que a proveniência seja irrelevante, e de fato até perigosa para a era digital. É um fardo do passado que devemos rejeitar.

Mas e se nós interpretarmos proveniência de forma diferente, não em termos de estruturas administrativas, onde a criação dos documentos e seu uso ocorreu, mas sim focar em primeiro lugar, e principalmente, na função da criação dos documentos e nas múltiplas relações de seu uso original e contínuo, então, uma nova vida toma lugar em nosso princípio central de definição de proveniência. O foco do princípio de proveniência se deslocaria para a função, atividade, discurso e comportamento, ao invés de, como no passado, permanecer centrado nas estruturas, cargos, mandatos e origem. Este fato abre a possibilidade de apresentar múltiplas origens e múltiplas ordens para situar os documentos ao invés de permitir uma única perspectiva. Esta nova abordagem adotaria metadados extensos e documentos de autoridade ao documentar esses elementos contextuais mais profundos; envolvendo a criação complexa, usos e relações de documentos através de toda sua história contínua, desde a sua entrada nos arquivos. A nova proveniência funcional refletiria a realidade dos documentos em seus contextos e histórias interrelacionadas, em constante evolução, abrindo ao invés de se fechar em ordens hierárquicas fixas.

Vários escritores chamaram esta nova e complexa proveniência de pós-custódia ou pós-moderna ou funcional; ou também denominada como proveniência ambiental ou social ou virtual; ainda 
tem sido descrita como uma busca de reconhecimento de padrões e coesão narrativa nos processos de criação de documentos. Em todos esses casos, o significado de proveniência é transformado de suas origens estruturalistas para um discurso contínuo centrado em funções, atividades, processos, forças sociais, e nas relações pessoais e organizacionais e culturas que coletivamente levam a criação de documentos, dentro e através de vidas pessoais e organizacionais em constante evolução. A nova proveniência oferece múltiplas perspectivas e muitas ordens de valor, ao invés de uma ordem fixa.

\section{InCID: Como então o senhor definiria proveniência neste novo mundo contextual da era digital que descreveu?}

Terry Cook: Eu diria que o princípio de proveniência deve focar no contexto dessas funções, processos e atividades da pessoa, grupo ou organização que leva à criação de documentos, dentro e através de organizações e vidas pessoais em constante evolução; interagindo com co-criadores e usuários (que estão em constante mudança) do documento, refletindo diferentes culturas organizacionais e de gestão, ou necessidades pessoais e psicológicas, e muitas vezes, idiossincráticas e sempre dinâmicas; convenções de trabalho e interação humana apropriadas para atividades, (frequentemente) de curto prazo, achatadas, horizontais, e em rede. Proveniência, em suma, está ligada virtualmente, através de múltiplas relações, fluídas e dinâmicas, entre a criação ou atividades de criação e o documento resultante e suas diversas audiências. Proveniência liga documentos a estas relações multifuncionais e de atividade, em vez de ao seu lugar estrutural de origem. A principal atividade intelectual e acadêmica do arquivista, em termos de descrição, é conduzir pesquisa sobre a história e a natureza dessas complexas relações, de modo que possamos iluminar, em todas as funções arquivísticas, para nós mesmos e para os nossos usuários, os ricos contextos que envolvem os documentos no mundo real.

Se me permite acrescentar a essa definição nós devolvemos aos documentos sua completa proveniência, transformando, desta forma, informações em nossos arquivos em possibilidades de conhecimento. Se nós, os arquivistas do mundo pudermos fazer isso, se pudermos mostrar aos pesquisadores e à sociedade, a rica proveniência dos documentos, então, em 50 ou 500 anos, os usuários de arquivos irão confiar na autenticidade dos documentos como evidência, porque o 
documento terá sido demonstrado a partir de um contexto real, fiável, crível e bem explicado, em vez de ser forçado em um quadro estruturalista simplista.

InCID: O senhor mencionou que rejeita a abordagem clássica da avaliação arquivística que foi apresentada por TR Schellenberg, de escolher documentos para a guarda arquivística de longo prazo, com base em tendências conhecidas ou esperadas de pesquisa futura. Por quê?

TerryCook: Além da impossibilidade de prever o futuro olhando para uma bola de cristal, a abordagem de Schellenberg "valor através do uso" para avaliação espelhando ou antecipando tendências históricas é repleta de dificuldades conceituais: o que dizer de tendências em constante mudança na historiografia, o que resultaria em documentos arquivísticos parecidos com uma colcha de retalhos, muito fragmentados, para não falar do risco destes documentos serem enviesados pelo lobby de um grupo bem organizado de usuários; e o que dizer de um crescente número de usuários de arquivos provenientes de uma grande variedade de disciplinas nãohistóricas (Biólogos, por exemplo, ou climatologistas, ou engenheiros, ou enfermeiros) para os quais a formação histórica do arquivista esclarece muito pouco; e os usuários não acadêmicos (genealogistas ou aficionados por ferrovias ou navios) e usuários de políticas públicas (como os que tratam com criminosos de guerra ou vários tipos de pedidos de indenização para enchentes ou desastres similares); e sobre arquivos como provas para a proteção dos direitos humanos de cidadãos e povos indígenas; ou ainda sobre arquivos sendo capazes de refletir cidadãos marginalizados na sociedade que não usam arquivos e cujas necessidades ou interesses seriam excluídos de qualquer medida de uso passado? Há dezenas de exemplos no Canadá, em todos os níveis de governo, desse tipo de problemas. Como o teórico arquivístico alemão Hans Booms brilhantemente observou, ligar avaliação à tendências e padrões históricos de uso, resulta em pouco mais do que arquivistas experientes e com educação em história que empregam "intuição sutil" baseada em sua "capacidade de empatia com os acontecimentos históricos... mesmo que eles normalmente não queiram admitir." Vários processos judiciais no Canadá lidando com a falta de documentos deixaram bem claro que avaliação baseada na empatia, intuição e experiência não constituem, nas palavras de Booms, "padrões de valor auto-evidentes", para dizer

InCID: R. Ci. Inf. e Doc., Ribeirão Preto, v. 3, n. 2, p. 142-156, jul./dez. 2012. 
o mínimo. Tal abordagem simplesmente já não era mais eticamente defensável numa era de maior responsabilização, incluindo responsabilização por parte dos arquivistas.

E além desses problemas conceituais com a abordagem de avaliação focada no uso, há também problemas metodológicos sérios. Como poderiam os arquivistas medir, eles próprios, padrões de uso passado (mesmo assumindo que a instituição arquivística tenha documentado muito bem esse processo ao longo de muitos anos) como um preditor válido de "valor" provável quando não há igualdade de condições em que esse uso ocorra: alguns documentos sendo restritos ao uso de dispositivos de acesso, fragilidade física ou fracos dispositivos de pesquisa; ainda outros documentos, sendo muito populares e intensamente utilizados em exposições arquivísticas e citados em muitos livros e artigos de pesquisadores, difundidos inclusive através de microfilmagem e digitalização de arquivos criando, portanto, um circuito auto perpetuador de mais e mais uso? Temos ainda, o uso baseado em calendário para conduzir avaliação arquivística, no final do "ciclo de vida" operacional do documento, que muitas vezes ocorreu várias décadas depois dos primeiros documentos serem colocados em arquivos que estão sendo avaliados. Esta passagem de tempo prolongada permitia que alguma perspectiva histórica se desenvolvesse de forma mais clara, como Schellenberg esperava. Mas o luxo do tempo não é mais possível. Dado o enorme volume de documentos em papéis na modernidade e seus períodos de retenção muito mais curtos com o objetivo de reduzir os enormes custos de armazenamento, e especialmente a transitoriedade tecnológica de suas contrapartes geradas por computador, agora a avaliação tem que ocorrer antes, durante, ou logo após a criação dos documentos, não algumas décadas depois.

\section{InCID: O senhor desenvolveu a "macro-avaliação" como uma melhor forma de conduzir avaliação arquivística. $O$ senhor pode descrever suas principais características?}

Terry Cook: Em resumo, numa única sentença, macro-avaliação avalia o valor social tanto do contexto funcional-estrutural como da cultura do local de trabalho em que os documentos são criados e usados pelo seu criador(es), e a inter-relação dos cidadãos, grupos, organizações— “o público"- com este contexto funcional-estrutural. Se a avaliação tradicional designa o valor a longo prazo do conteúdo dos documentos, ou uma série de documentos, por seu valor potencial de investigação, a macro-avaliação avalia a importância do contexto funcional de sua criação e 
uso contemporâneo. A avaliação trata de documentos enquanto que a macro-avaliação trata de seu contexto mais amplo (ou "macro").

Retornando a este foco social que forma a base conceitual ou teórica da macro-avaliação, os sociólogos postularam que todas as sociedades refletem, em diferentes graus, uma interação de três vias de estruturas sociais, funções sociais, e cidadãos (individualmente ou como membros de diversos grupos sociais). De modo correspondente, a macro-avaliação procura sugerir como tais valores sociais podem ser determinados na realidade, analisando os atributos e especiais pontos de intersecção (e às vezes, de conflito), entre estas três entidades contextuais inter-relacionadas: 1) os criadores de documentos (ou seja, estruturas, agências, instituições, burocratas), 2) os processos sócio-históricos (isto é, funções, programas, atividades, transações- serviços- que o Estado oferece aos cidadãos, e que os cidadãos demandam do governo) e 3) os cidadãos, clientes, constituintes, ou grupos, os quais estas funções e estruturas afetam, e que por sua vez influenciam tanto a função como a estrutura, direta ou indiretamente, explícita ou implicitamente. A macroavaliação requer que os arquivistas pesquisem a natureza desses agentes e ações, e especialmente, as interconexões e inter-relações entre eles e, em seguida, atribuam maior importância, ou "valor" a certos fatores funcional-estruturais e interações dos cidadãos em comparação aos outros. A macro-avaliação é, portanto, uma abordagem de avaliação baseada na proveniência, onde o contexto social da criação de documentos e uso contemporâneo (e não o que se imagina de uso de pesquisa) estabeleça o seu valor relativo. Portanto, a macro-avaliação também reflete novas e mais ricas concepções sobre proveniência que eu mencionei no início da entrevista.

Esta análise funcional para arquivistas significa que o ambiente contextual em que os documentos são criados é determinado por todos esses fatores: macro-funções, funções, sub-funções, estruturas e instituições) e, por sua vez, pelas suas culturas organizacionais, programas, atividades, e transações e especialmente interações com clientes, bem como por processos de criação de documentos, sistemas de manutenção de registros, e diferentes meios de registro e tecnologias de registro. Ao focar a pesquisa de avaliação arquivística na análise e avaliação, isto é, "avaliando" a importância destas funções, programas e atividades e interações dos cidadãos, em primeira instância, ao invés de avaliar milhares de milhões de documentos, ou dezenas de milhares de sistemas, séries e coleções de documentos, o arquivista é capaz de ver toda a floresta, ao invés de apenas algumas árvores. A visão de todo o contexto, em última análise, significa que 
os documentos mais pobres e duplicados são mais facilmente identificados e eliminados, e que o documento mais sucinto, disponível na melhor mídia e na melhor localização para uma determinada função, é mais facilmente avaliado para a preservação arquivística. Se a apreciação do valor de documentos, tradicionalmente, tem sido chamada de "avaliação", então a apreciação deste universo funcional maior é apropriadamente chamada de "macro-avaliação." E se a pesquisa feita pelo arquivista nesta matriz funcional-estrutural é completa e reflete diferentes nuances, os documentos resultantes, identificados como arquivísticos, irão melhor refletir os "valores sociais", simplesmente porque a macro-avaliação olha para os processos (e para suas evidências documentais) enquanto que a sociedade se forma (e continuamente se re-forma) de acordo com seus próprios valores em constante mudança. Portanto, ao fazer isso, a macroavaliação combina uma decomposição funcional de "cima para baixo" de desejos amplos da sociedade expressos através do parlamento nas funções e atividades do Estado com uma atenção "de baixo para cima" considerando a interação corretiva do cidadão com esse estado.

Movendo-se deste modelo teórico para a estratégia implementável, a macro-avaliação muda o foco inicial e principal de avaliação do documento- e quaisquer valores de pesquisas futuras que o mesmo possa conter- para o contexto funcional em que o documento é criado. A macroavaliação, portanto, foca na proveniência conceitual, virtual ou funcional do tipo que discutimos anteriormente. Usando conhecimentos obtidos com pesquisa, através da análise funcional do arquivista, incluindo uma análise da interação da função e estrutura, de organização dinâmica cultural, de sistemas de manutenção de documentos, e do envolvimento e interação do cidadão/cliente com a instituição ou função, o arquivista, quando faz uma avaliação, faz três grandes conjuntos de perguntas: 1) quais são as funções e atividades mais importantes do criador a serem documentadas (ao invés de qual documentação deve ser mantida)? 2) quem- na coordenação e implementação dessas funções-chave, programas e operações da instituiçãoteria a responsabilidade principal de criar um documento, que tipo de documento seria, e com quem essa pessoa corporativa interagiria, tanto em sua criação como em seu uso operacional posterior? e 3) como é que o cidadão interage com este universo funcional, e como é que os cidadãos tem geralmente aceitado e apoiado, ou protestado e desafiado os programas e serviços relacionados? Somente depois que essas perguntas são respondidas através de uma metodologia de pesquisa de macro-avaliação, o arquivista pode então focar realisticamente os verdadeiros documentos, ou série de documentos, que provavelmente têm maior valor potencial arquivístico 
para o processo, que para distingui-lo da macro-avaliação, poderia ser chamado de "microavaliação" (isto é, avaliação tradicional aplicando "critérios" tais como idade, extensão, singularidade, intervalo de tempo, completude, afinidade/relação com outros registros, fragilidade, confiabilidade, manipulabilidade, etc.) em qualquer nível maior de detalhes que possa garantir ou que os recursos permitam. A macro-avaliação não ignora a micro-avaliação, ou características específicas da mídia, mas apenas a coloca em um lugar ou contexto mais lógico. Claro, bem antes da fase da micro-avaliação, as respostas (baseadas em pesquisa do arquivista) para as três maiores questões em nível macro, mencionadas há pouco, significa que grandes volumes de documentos podem ser destruídos sem uma investigação mais aprofundada no nível micro, poupando agências e arquivos, tempo, espaço, trabalho e dinheiro consideráveis no processo de avaliação e eliminação de documentos.

Quarenta anos atrás, Hans Booms desafiou a profissão arquivística ao documentar a sociedade ativamente, estrategicamente, e de forma cuidadosa. Com efeito devastador, ele mostrou que as teorias de avaliação do passado deixavam o arquivista nu, um imperador sem roupas, selecionando arquivos por intuição ou com desinteresse, privilegiando assim, criadores poderosos ou usuários influentes. Metodologias de avaliação baseadas em tais pressupostos teóricos são indefensáveis e, portanto, não podem ser levadas em conta, e eu acrescentaria, são antiéticas. A subjetividade inevitável e impacto significativo de uma avaliação arquivística pode muito bem intimidar os arquivistas que enfrentam o desafio honestamente, mas Booms aconselhou, tal “jornada exige apenas que o viajante possua o insight e a vontade de chegar às conclusões necessárias e agir sobre as mesmas.” A macro-avaliação é esta jornada.

\section{InCID: O senhor mencionou que estudou a história arquivística? Poderia nos contar o que aprendeu com isso?}

Terry Cook: Meu discurso em plenário no Congresso Internacional de Arquivos em Pequim, em 1996, foi uma análise da história das ideias dos arquivos por arquivistas, desde a publicação do manual holandês em 1898. Esse discurso foi bastante expandido num artigo para a Archivaria e foi traduzido para 10 ou mais idiomas. Eu também estudei a história dos arquivos, de forma mais geral, no Canadá, e o próprio Arquivo Nacional do Canadá em maior detalhe, e as biografias de alguns arquivistas líderes. Devo reconhecer que minhas limitações linguísticas significam que 
estou baseando minhas conclusões na evolução histórica das ideias arquivísticas e da profissão de arquivista nas investigações históricas em países de idioma inglês como o Canadá, Estados Unidos, Austrália, Nova Zelândia e África do Sul; bem como nas ideias europeias que foram traduzidas para o idioma inglês, principalmente da Holanda, França, Itália e Alemanha. No entanto, minhas conclusões parecem ter relevância, em termos gerais, em discussões com arquivistas de outras áreas linguísticas, incluindo Portugal, Espanha, Noruega, China, e assim por diante. No meu ponto de vista, a análise da história das ideias arquivísticas requer ouvir o discurso arquivístico do tempo ou lugar envolvidos. A análise arquivística histórica requer revisitar as principais discussões profissionais que os arquivistas líderes tinham sobre o seu trabalho e um com o outro. Exige ouvir novamente, e obter compreensão dentro do contexto de seu tempo, e o nosso próprio, os seus pressupostos, ideias e conceitos.

Nesta abordagem, "teoria" arquivística e "teórico" arquivístico, não se referem, respectivamente, a um conjunto imutável de princípios fixos e seus defensores constantes em vários domínios da prática. Esse tipo de perspectiva histórica é demasiado Positivista e ultrapassada para um observador do final do século XX adotar, apesar de que essa era a posição tradicional arquivística até por volta de 1980. Em vez disso, o pensamento arquivístico, ao longo do século passado deveria ter sido visto como em constante evolução, sempre em mutação, uma vez que se adapta à mudanças radicais na natureza dos documentos, organizações que sempre criam documentos, sistemas de manutenção de documentos, usos de documentos, e de tendências mais amplas em termos culturais, legais, tecnológicos, sociais e filosóficos na sociedade. Ideias arquivísticas formadas em um tempo e lugar refletem muitos desses fatores externos, cujas ideias são muitas vezes reconstruídas, mesmo redescobertas em outro tempo e lugar, ou reformuladas ao longo de gerações no mesmo lugar. Os melhores teóricos arquivísticos são aqueles que têm sido capazes de reconhecer e expressar essas mudanças radicais na sociedade e, então, lidar conceitualmente com o seu impacto na teoria e prática arquivística. Essa expressão forma nosso discurso coletivo, o meta-texto ou narrativa animando nossa prática profissional e, desta forma, é o foco devido de uma história intelectual de arquivos. 


\section{InCID: O senhor percebe determinadas fases históricas em arquivos modernos? Qual foi a nossa meta-narrativa ao longo do século passado?}

Terry Cook: Eu acredito que há quatro estruturas amplas, ou maneiras de pensar, ou "paradigmas", sobre arquivos - tanto em ideias como ações. Já passamos por dois destes e, estamos no terceiro, e o quarto está se apresentando muito fortemente, e é a nossa esperança para o futuro. Eu só posso resumi-los aqui, e remeter o leitor para um artigo que está prestes a ser publicado na revista Archival Science onde eu lido com este assunto de forma muito mais detalhada. Eu nomeei estes quatro paradigmas de evidência, memória, sociedade e comunidade.

O primeiro paradigma arquivístico foca na guarda de um resíduo "natural" de documentos mais antigos como evidência, e o foco principal da profissão do arquivista, como guardião imparcial, estava no arranjo e descrição para colocar esse resíduo jurídico no contexto para uso e entendimento pela posteridade como fontes documentais autênticas e confiáveis. Evidência foi o conceito-chave do primeiro paradigma, e este conceito dominou o discurso profissional até a década de 1930, e continua até o presente como uma preocupação importante na área. Hilary Jenkinson foi o pensador chave no mundo onde se fala o idioma inglês.

O segundo paradigma arquivístico estava claramente preocupado com a avaliação de documentos como fontes históricas, com o historiador-arquivista criando de forma subjetiva um recurso de memória cultural, em vez de guardar um legado jurídico herdado de evidência mais antiga. Este recurso de memória foi gerido de forma mais eficiente por empresas cada vez maiores usando ferramentas empresariais e processos modernos, para apoiar novas abordagens para avaliação e descrição. O arquivo resultante era, é claro, ainda evidência de atividade humana e organizacional, mas o contexto em que essa evidência foi criada, avaliada, adquirida, descrita e entendida, tinha se transformado. Memória é o conceito-chave do segundo paradigma arquivístico, que floresceu de 1930 a 1970, antes de mostrar suas fraquezas. Theodore Schellenberg foi o pensador chave aqui.

O terceiro paradigma arquivístico estava claramente focado em arquivos como um recurso social, que era discernido, avaliado, adquirido e descrito por arquivistas, por direito próprio, como especialistas em documentos, para uma grande variedade de usos, um recurso da sociedade que respeitava cada vez mais a natureza pluralista e ambígua do mundo pós-moderno e digital ao invés dos padrões monolíticos que tinham dominado as estruturas arquivísticas anteriores, fossem 
estas jurídicas ou históricas. Arquivos também deixaram de ser um recurso cultural e de patrimônio subjacente à elite acadêmica para se tornar uma base social para a identidade e justiça. A própria identidade do arquivista foi ancorada em ser o especialista liderando a sociedade para encontrar sua identidade através de memórias compartilhadas fundamentado em concepções mais sofisticadas de evidência. Identidade é o conceito-chave do terceiro paradigma- a busca da própria identidade do arquivista como um mediador consciente ajudando a sociedade na formação de suas múltiplas identidades recorrendo à memória arquivística e como um agente ativo protegendo evidência em face da complexidade acelerada de organizações sociais e mídia digital em mudança rápida.

O desafio para arquivistas agora em 2012 é alcançar arquivos mais democráticos, inclusivos, holísticos, coletivamente escutando muito mais aos cidadãos do que o Estado, bem como respeitando as formas de conhecimento, evidência e memória natural do país, ao invés do que ocorreu nos primeiros três paradigmas. Para documentos ainda adquiridos pelos arquivos convencionais, como a estratégia de documentação de Helen Samuels há muito expressada, a avaliação e aquisição seria colaborativa e cooperativa e interativa, online, e assim também seria a descrição e preservação, a fim de encontrar a melhor localização para a preservação dos melhores documentos com máximo de contexto participativo-iluminado- uma Wikipedia para fontes arquivísticas. Além do que os arquivos já estabelecidos adquirem, existe um grande número de documentos remanescentes em comunidades que lançam uma luz importante na sociedade. Ao invés de tirar tais registros de suas comunidades, o novo modelo sugere capacitar essas comunidades para cuidar de seus próprios registros, especialmente seus documentos digitais, em parceria com perícia archivística profissional e infraestruturas arquivísticas digitais, juntamente com o profundo sentido de compromisso e orgulho das comunidades no seu próprio património e identidade. Comunidade é o conceito chave do quarto paradigma arquivístico, agora, ficando à vista, uma democratização de arquivos apropriada ao ethos social, aos padrões de comunicação e requisitos comunitários da era digital.

Concluindo, creio que os paradigmas arquivísticos têm variado através de quatro fases: de legado jurídico à memória cultural à engajamento social à arquivamento na comunidade. $\mathrm{O}$ arquivista foi transformado, de acordo com estas quatro fases, de guardião passivo à avaliador ativo à mediador da sociedade à facilitador da comunidade. $\mathrm{O}$ foco do pensamento arquivístico passou igualmente 
de evidência à memória à identidade e à comunidade, assim como as correntes intelectuais mais amplas da sociedade mudaram de pré-moderna à moderna à pós-moderna e à contemporânea. É claro que há sobreposições. Vertentes de todos as quatro mentalidades estão interligadas. Esta discussão trata da ênfase, não de definição rígida. Mas na comunidade arquivística, pode ser que nós arquivistas, sejamos capazes de descobrir uma nova identidade que concilie nossas missões individuais (e muitas vezes tradições antagônicas) de evidência e memória.

E assim fazendo, podemos entender melhor e, portanto, enriquecer nosso próprio senso de comunidade de arquivistas. Essa comunidade deveria ser capaz de abraçar as diferenças ao invés de estar fundada ou numa mitologia animada ou na exclusão dos diferentes e "outros," enquanto a evidência defende a minimização da memória e destituição de seus defensores, mediadores nãoarquivísticos ou, vice-versa, a memória defende descartar guardiões de evidência como estritamente legalista. Ao ancorar suas atividades e abordagens cada vez mais diversificadas, através de um envolvimento com o que as comunidades viviam e suas práticas evidênciamemória-identidade, a prática (e identidade) arquivística pode permanecer plural e diversificada, sem se tornar simplesmente fraturada em campos desconectados ou dilacerada por lutas pela supremacia de uma escola de pensamento versus outra. A comunidade arquivística, como um modelo, tem muito a oferecer aos arquivistas, assim como os arquivistas têm muito a oferecer à comunidade arquivística.

Eu acredito que a comunidade arquivística mantém a promessa de maior habilidade para abrigar a pluralidade, diversidade e diferença (tanto em termos de nossas próprias práticas divergentes, através de espaço, tempo e tradições, como em termos de comunidades sociais e culturais muito diferente com as quais nos envolvemos.) Vendo paradigmas arquivísticos mudando através do tempo, através do estudo da história arquivística, cada era interpreta novamente evidência e memória, e assim, redefine a identidade arquivística e sua relação com as comunidades sociais, nos libertando para abraçar novas direções mais uma vez para a era digital. A alternativa, como o arquivista teórico canadense Hugh Taylor nos alertou, é correr o risco de nos tornarmos fósseis flutuando nos remansos estagnados de irrelevância social.

Entrevista enviada em: nov. 2012

InCID: R. Ci. Inf. e Doc., Ribeirão Preto, v. 3, n. 2, p. 142-156, jul./dez. 2012. 